\title{
Downregulation of astrocyte elevated gene-1 expression inhibits the development of vasculogenic mimicry in gliomas
}

\author{
CHEN LIANG $^{1}$, JIAN SHANGGUAN ${ }^{1}$, LING YANG $^{2}$ and SHIWEN GUO ${ }^{1}$ \\ ${ }^{1}$ Department of Neurosurgery, First Affiliated Hospital of Xi'an Jiaotong University, Xi'an, Shaanxi 710061; \\ ${ }^{2}$ Department of Aeromedical Physical Examination, Xi'an Civil Aviation Hospital, Xi'an, Shaanxi 710082, P.R. China
}

Received April 17, 2019; Accepted October 14, 2020

DOI: $10.3892 / \mathrm{etm} .2020 .9454$

\begin{abstract}
Vasculogenic mimicry (VM) contributes to the resistance of anti-angiogenic therapies in glioma. Certain genes, including MMP-2 and VEGF may be associated with the development of VM. Astrocyte elevated gene-1 (AEG-1) is considered to be an oncogene that promotes autophagy, invasion, metastasis, angiogenesis and drug resistance; however, the association between AEG-1 and VM formation is still unknown. The present study investigated the effects of AEG-1 downregulation on VM formation in the U87 glioma cell line in vitro and in xenograft models of glioma, and the potential underlying mechanisms of action. In the present study, U87 glioma cells were infected with the AEG-1 short hairpin RNA lentivirus. A Matrigel-based tube formation assay was performed to evaluate VM formation in vitro. Reverse transcription-quantitative PCR and western blot analysis were conducted to investigate the mRNA and protein expression levels of MMP-2 and VEGF. Glioma xenograft models were generated through the intracerebral implantation of U87 glioma cells into nude rats; CD34/Periodic Acid-Schiff double-staining was performed to detect VM channels in vivo. Following AEG-1 downregulation in U87 cells, the development of VM was significantly decreased in vitro and in vivo. In addition, the expression levels of MMP-2 and VEGF in glioma cells were decreased compared with the control group. These results suggested that downregulation of AEG-1 expression could significantly inhibit the development of VM in gliomas, both in vitro and in vivo, and may be partially related to the regulation of VEGF and MMP-2 expression.
\end{abstract}

\section{Introduction}

Glioma is the most common type of primary malignant brain tumor in adults, constituting $\sim 81 \%$ of all primary

Correspondence to: Professor Shiwen Guo, Department of Neurosurgery, First Affiliated Hospital of Xi'an Jiaotong University, 277 Yanta West Road, Xi'an, Shaanxi 710061, P.R. China

E-mail: guoshiwen1962@126.com

Key words: astrocyte elevated gene-1, glioma, vasculogenic mimicry malignant brain tumors (1). Standard therapeutic regimens, including surgical resection combined with radiotherapy and temozolomide chemotherapy, can prolong the survival of patients with tumors characterized by methylation of the O-6-methylguanine DNA methyltransferase promoter; however, the median duration of survival of patients with glioblastoma multiforme (GBM), a high-grade glioma, is $<1.5$ years (2). Gliomas, particularly GBM, exhibit a high degree of angiogenesis, as determined by histological analysis (3). Angiogenesis serves an important role in the formation, development and recurrence of gliomas; anti-angiogenic therapy has been considered as a novel strategy for treating patients with gliomas (4). In addition, studies have proposed that anti-angiogenic therapeutic regimens can improve the outcome of patients with gliomas, yet its clinical effect remains unsatisfactory (5). Recently, glioma cells have been reported to exhibit vasculogenic mimicry (VM), in which extracellular matrix (ECM)-rich, vasculogenic-like networks form and allow glioma cells to obtain a blood supply in the absence of endothelial cell (EC)-dependent vasculature (6). Anti-angiogenic agents aim to inhibit the formation of endothelium-dependent vessels but not the development of VM, which may partially contribute to the failure of anti-angiogenic therapy (7). Several studies have demonstrated that certain genes, including MMP-2, VEGF, membrane type-1 MMP (MT1-MMP), cyclooxygenase-2 and vascular endothelial cadherin (VE-cadherin), may be involved in the formation of VM in tumors. Agents targeting these genes have been determined to exhibit anti-VM effects (7).

Astrocyte elevated gene-1 (AEG-1) is a downstream gene of Ha-ras and cyclin D1, and can activate the NF- $\mathrm{B}, \mathrm{PI} 3 \mathrm{~K} / \mathrm{Akt}$ and Wnt signaling pathways, serving an important role in invasion, metastasis, angiogenesis and chemoresistance in a variety of tumor types, including gliomas $(8,9)$. AEG-1 can promote the progression and invasion of gliomas through a variety of mechanisms, including the induction of protective autophagy (8) and suppression of the formation of reactive oxygen species induced by hypoxia (9). Silencing AEG-1 in glioma cells can significantly induce tumor cell apoptosis and inhibit tumor growth $(8,10)$; however, whether AEG-1 participates in VM formation in gliomas remains unknown.

The present study aimed to investigate the effects of AEG-1 downregulation on VM formation in gliomas in vitro and 
in vivo using the U87 cell line and glioma xenograft models, respectively, to obtain further insight into the underlying mechanisms of action.

\section{Materials and methods}

Materials. The U87 MG human glioblastoma cell line of unknown origin (cat. no. TCHu138) and 293T cell line were purchased from The Cell Bank of Type Culture Collection of the Chinese Academy of Sciences. STR profiling was conducted for the authentication of the U87 MG cell line, according to the supplier's description. A total of 30 male, 7-9 week old, specific pathogen-free, Rowett nude rats (Crl:NIH-Foxn1rnu), weighing 180-240 g, were purchased from Vital River Laboratory Animal Technology Co., Ltd., and were housed in a full-barrier rodent facility with a filtered air supply, constant temperature $\left(22 \pm 1^{\circ} \mathrm{C}\right)$ and humidity $(50-60 \%)$ under a 12 -h light/dark cycle. The housing environment for animals, water and animal feeds were sterilized. All rats had free access to food and water. All animal procedures were performed under the guidance of the Research Ethics Committee of Xi'an Jiaotong University Health Science Center (Xi'an, China).

Cell culture. U87 and 293T cells were cultured in DMEM (Gibco; Thermo Fisher Scientific, Inc.) supplemented with $10 \%$ FBS (Hyclone; GE Healthcare) in an atmosphere of $5 \% \mathrm{CO}_{2}$ at $37^{\circ} \mathrm{C}$.

Design and synthesis of $P C R$ primers and $A E G-1$ small interfering RNA (siRNA). The primers for VEGF, MMP-2, $\beta$-actin, AEG-1 and AEG-1 siRNA were designed and synthesized by Takara Bio Inc. (Table I).

siRNA transfection. U87 cells were trypsinized and seeded in 6-well plates (Corning Inc.) at a density of $1 \times 10^{6}$ cells/well. Lipofectamine ${ }^{\circledR} 3000$ (Invitrogen; Thermo Fisher Scientific, Inc.) was used for the transfection of siRNA into cells according to the manufacturer's protocols. The negative control cells were transfected with a scrambled siRNA (Takara Bio, Inc.), while the other two groups were transfected with AEG-1 siRNA1, AEG-1 siRNA2 or AEG-1 siRNA3. The transfection was performed at room temperature for $15 \mathrm{~min}$. After incubation for $48 \mathrm{~h}$ at $37^{\circ} \mathrm{C}$, the transfected cells were analyzed. The knockdown efficiency of siRNAs was verified using reverse transcription-quantitative PCR (RT-qPCR) and western blotting. The siRNA with the highest knockdown efficiency was selected to construct the AEG-1 short hairpin (sh)RNA lentiviral particle, while the scrambled siRNA was used to construct the sh-control lentiviral particle.

AEG-1 shRNA lentiviral infection. The $\mathrm{pLVX-shRNA2-puro}$ (cat. no. VT2240), psPAX2 (cat. no. VT1444) and pMD2.G plasmids (cat. no. VT1443) were purchased from Hunan Keai Medical Equipment Co., Ltd (https://www.youbio. $\mathrm{cn} /$ product/). According to the selected siRNA sequence, the shRNA sequence was constructed and cloned into the pLVX-shRNA2-puro plasmid and lentiviral particles were produced via the transduction of $293 \mathrm{~T}$ cells with $3 \mu \mathrm{g}$ of AEG-1 shRNA plasmid, $1.5 \mu \mathrm{g}$ psPAX2 and $1.5 \mu \mathrm{g}$ pMD2.G. Lentiviral supernatants were then collected after $48 \mathrm{~h}$. The construction of sh-control lentiviral vectors was conducted as aforementioned. U87 cells were then infected with concentrated AEG-1 shRNA or sh-control lentiviral vectors $(\mathrm{MOI}=10)$, and the stable transfected cell line was selected using $1 \mu \mathrm{g} / \mathrm{ml}$ puromycin (Gibco; Thermo Fisher Scientific, Inc.).

$R T-q P C R$. The U87 cells in each group were harvested $48 \mathrm{~h}$ after infection with AEG-1 shRNA lentivirus. The cells were then lysed and the total RNA was isolated using an RNA Fast 200 kit (Shanghai Fastagen Biotechnology Co., Ltd.) according to the manufacturer's instructions. RNA was reverse-transcribed using PrimeScript ${ }^{\mathrm{TM}}$ RT Master Mix kit (Takara Bio, Inc.). The temperature protocol for reverse transcription was $37^{\circ} \mathrm{C}$ for $15 \mathrm{~min}$ and $85^{\circ} \mathrm{C}$ for $5 \mathrm{sec}$ ). qPCR was performed using SYBR ${ }^{\circledR}$ Premix Ex Taq II (Takara Bio, Inc.) on an iQ5 thermal cycler (Bio-Rad Laboratories, Inc.). The thermocycling conditions were as follows: Initial denaturation at $95^{\circ} \mathrm{C}$ for $3 \mathrm{~min}$, followed by 40 cycles of $95^{\circ} \mathrm{C}$, for $5 \mathrm{sec}$, $63^{\circ} \mathrm{C}$ for $30 \mathrm{sec}$ and $72^{\circ} \mathrm{C}$ for $15 \mathrm{sec}$ and analyzed using iQ5 software, version 2.0 (Bio-Rad Laboratories, Inc.). The data were normalized to the expression of $\beta$-actin. Alterations in gene expression were evaluated using the $2^{-\Delta \Delta \mathrm{Cq}}$ method (11).

Western blotting. The U87 cells in each group were harvested $48 \mathrm{~h}$ after infection with AEG-1 shRNA lentivirus. The extraction of total cellular proteins and the western blot analysis were performed as described previously (12). Briefly, the cells were washed twice with PBS and scraped on ice following the addition of $300 \mu 1$ RIPA buffer (Beyotime Institute of Biotechnology) with $1 \mathrm{mmol} / \mathrm{l}$ phenylmethylsulfonyl fluoride. Protein concentration was determined using a bicinchoninic acid protein assay kit (Beyotime Institute of Biotechnology). The samples $(40 \mu \mathrm{g})$ were boiled in 1X SDS-PAGE sample loading buffer, resolved using 10\% SDS-PAGE and transferred onto polyvinylidene fluoride (PVDF) membranes (EMD Millipore). The membranes were then blocked in TBS- $0.1 \%$ Tween-20 (TBST) containing 5\% non-fat dry milk at room temperature for $2 \mathrm{~h}$. The membranes were probed with primary antibodies overnight at $4{ }^{\circ} \mathrm{C}$ and incubated with a secondary polyclonal anti-rabbit immunoglobulin $\mathrm{G}(\operatorname{IgG})$ antibodies conjugated to horseradish peroxidase (cat. no. BA1054; 1:5,000; Boster Biological Technology;) at $37^{\circ} \mathrm{C}$ for $2 \mathrm{~h}$. Membranes were developed using SuperSignal ${ }^{\mathrm{TM}}$ West Pico PLUS Chemiluminescent Substrate (Thermo Fisher Scientific, Inc.). The primary antibodies employed for western blotting were as follows: Rabbit anti-human MMP-2 (dilution, 1:500; cat. no. BS1236) and rabbit anti-human GAPDH (dilution, 1:5,000; cat. no. ap0063), which were purchased from Bioworld Technology, Inc. Rabbit anti-human AEG-1 antibody was purchased from ProteinTech Group, Inc. (dilution, 1:1,000; cat. no. 13860-1-AP). Rabbit anti-human VEGF antibody was purchased from Abcam (dilution, 1:1,000; cat. no. ab53465).

In vitro VM formation assay. A Matrigel-based tube formation assay (13) was conducted to analyze VM formation in vitro. Briefly, Matrigel (Becton, Dickinson and Company) was maintained at $4^{\circ} \mathrm{C}$ for $24 \mathrm{~h}$, after which $0.3 \mathrm{ml}$ of Matrigel was evenly plated to 24-well plates (Corning Inc.) and precooled at $-20^{\circ} \mathrm{C}$ for $\geq 10 \mathrm{~min}$ and then incubated for $30 \mathrm{~min}$ at $37^{\circ} \mathrm{C}$. 
Table I. Sequences for reverse transcription-quantitative PCR primers, siRNAs and shRNAs.

\begin{tabular}{ll} 
Gene & \multicolumn{1}{c}{ Sequences } \\
\hline VEGF & Forward, 5'-TCACAGGTACAGGGATGAGGACAC-3' \\
& Reverse, 5'-CAAAGCACAGCAATGTCCTGAAG-3' \\
MMP-2 & Forward, 5'-CTCATCGCAGATGCCTGGA A-3' \\
& Reverse, 5'-TTCAGGTAATAGGCACCCTTGAAGA-3' \\
$\beta$-actin & Forward, 5'-TGGCACCCAGCACAATGAA-3' \\
& Reverse, 5'-CTAAGTCATAGTCCGCCTAGAAGCA-3' \\
AEG-1 & Forward, 5'-CACGCCATGATGGAAAGGAAGT-3' \\
& Reverse, 5'-CAGGAAATGATGCGGTTGTAAG -3' \\
AEG-1 siRNA1 & Sense, 5'-GCCGUAAUCAACCCUAUAUTT-3' ' \\
& Antisense, 5'-AUAUAGGGUUGAUUACGGCTT-3' \\
AEG-1 siRNA2 & Sense, 5'-GCUGUUCGAACACCUCAAATT-3' \\
& Antisense, 5'-UUUGAGGUGUUCGAACAGCTT-3' \\
AEG-1 siRNA3 & Sense, 5'-GCCAUCUGUAAUCUUAUCATT-3' \\
Scrambled siRNA & Antisense, 5'-UGAUAAGAUUACAGAUGGCTT-3' \\
& Sense, 5'-GACGCATATTGACCTCACTAT-3' \\
AEG-1 shRNA & Antisense, 5'-ATAGTGAGGTCAATATGCGTC-3' \\
Scrambled shRNA & 5'-GCTGTTCGAACACCTCATATTCAAGAGATATGAGGTGTTCGAACAGCTTTTT-3' \\
& 5'-GACGCATATTGACCTCACATTCAAGAGATGTGAGGTCAATATGCGTCTTTTT-3'
\end{tabular}

AEG-1, astrocyte elevated gene-1; VEGF, vascular endothelial growth factor; MMP, matrix metalloproteinase.

Subsequently, U87 cells $\left(3 \times 10^{4}\right.$ cells/well) were seeded onto the Matrigel coated wells $48 \mathrm{~h}$ following transduction and incubated for $24 \mathrm{~h}$ in a $5 \% \mathrm{CO}_{2}$ atmosphere at $37^{\circ} \mathrm{C}$. Each well was analyzed directly under an inverted fluorescent microscope (magnification, x100; IX51; Olympus Corporation). VM formation was determined by counting the number of tubes in each well. The tubes comprised a closed cavity with a loop structure, a polygon shape or irregular shape under a light microscope.

Animal studies. The establishment of intracranial xenograft models was conducted as described previously (10). A total of 30 nude rats were randomly divided into three groups (10 rats/group). Animals were anaesthetized with intraperitoneal injection of $30 \mathrm{mg} / \mathrm{kg} 1 \%$ pentobarbital sodium. The AEG-1 shRNA and negative control groups were injected intracranially with AEG-1 shRNA or sh-control lentivirus-infected U87 cells. The control group was injected with normal U87 cells. All tumor-bearing rats were sacrificed 3 weeks following tumor cell implantation. The euthanasia method was intraperitoneal injection of $200 \mathrm{mg} / \mathrm{kg}$ pentobarbital sodium solution. Cardiac arrest was used to identify death. The humane endpoints included labored breathing, inability to remain upright, impaired mobility, hunched posture for more than $48 \mathrm{~h}$ and no response to external stimuli. Rats were perfused with $4 \%$ paraformaldehyde for $1 \mathrm{~h}$ at $4^{\circ} \mathrm{C}$ immediately after euthanasia, before the brain and tumor samples were obtained and fixed overnight with $4 \%$ paraformaldehyde at $4^{\circ} \mathrm{C}$. Paraffin sections were prepared and the thickness of sections was $4 \mu \mathrm{m}$.
$V M$ formation detection in xenograft models. CD34 and Periodic Acid-Schiff (PAS) double-staining was performed to detect VM channels. An immunohistochemical assay kit (Boster Biological Technology) was employed for the immunohistochemical staining of CD34. All procedures were performed according to the manufacturer's protocols. The sections were incubated overnight with rabbit anti-CD34 antibody (1:200; Boster Biological Technology; cat. no. BA3414) at $4^{\circ} \mathrm{C}$. The negative control sections were incubated with PBS instead of antibody. Antibody localization was determined using a 3,3'-diaminobenzidine substrate kit (Boster Biological Technology). Normal vascular endothelium was used as a positive control.

Following immunohistochemical staining, the sections were exposed to sodium periodate for $5 \mathrm{~min}$ and then washed with distilled water three times. Subsequently, the sections were incubated with PAS at room temperature for $15 \mathrm{~min}$. All sections were counterstained with hematoxylin at room temperature for $2 \mathrm{~min}$. VM channels were characterized as $\mathrm{CD}^{2} / \mathrm{PAS}^{+}$lumen structures. The average number of VM channels were calculated from the analysis of five fields under the light microscope at high magnification (x400).

Statistical analysis. Values are presented as the mean \pm SD and data were analyzed using SPSS 17.0 software (SPSS, Inc.). One-way ANOVAs were used to compare the groups and the Least Significant Difference or Tukey's post-hoc tests were performed to further determine inter-group comparisons. $\mathrm{P}<0.05$ was considered to indicate a statistically significant difference. 


\section{Results}

AEG-1 siRNA and AEG-1 shRNA lentivirus inhibits AEG-1 expression in U87 glioma cells. As presented in Fig. 1, after transduction with AEG-1 siRNAs, the mRNA and protein expression levels of AEG-1 were significantly downregulated in U87 glioma cells, compared with the control and negative control groups $(\mathrm{F}=1080.231, \mathrm{P}<0.001)$. AEG-1 siRNA2 exhibited the highest knockdown efficiency among the three AEG-1 siRNAs ( $\mathrm{P}=0.035$ vs. siRNA1; $\mathrm{P}=0.002$ vs. siRNA3) and was selected to construct the AEG-1 shRNA lentiviral particle employed for subsequent experiments. After infection with AEG-1 shRNA lentivirus, green fluorescence can be clearly observed in the U87 glioma cells. The expression of AEG-1 was significantly downregulated in the stably transfected U87 glioma cells, compared with the control and negative control groups $(\mathrm{F}=85.082, \mathrm{P}<0.001)$.

Downregulation of AEG-1 expression inhibits VM formation of U87 glioma cells in vitro. The VM formation of U87 glioma cells was observed in vitro following infection with AEG-1 shRNA lentivirus. As presented in Fig. 2A and B, downregulation of AEG-1 expression significantly inhibited the VM formation of U87 glioma cells, compared with control groups $(\mathrm{F}=65.396, \mathrm{P}<0.001)$.

Downregulation of AEG-1 expression inhibits MMP-2 and VEGF expression in U87 glioma cells. As MMP-2 and VEGF have been reported to be involved in VM formation in tumors (14), the expression levels of these genes in U87 cells were detected using RT-qPCR and western-blotting. As presented in Fig. 2C and D, downregulation of AEG-1 significantly inhibited the expression of VEGF and MMP-2 $(\mathrm{F}=267.471, \mathrm{P}<0.001$ for $\mathrm{VEGF}$ mRNA; $\mathrm{F}=3671.526, \mathrm{P}<0.001$ for MMP2 mRNA).

Downregulation of AEG-1 expression inhibits VM formation in a glioma xenograft model. CD34 and PAS double-staining was used to detect VM formation in a glioma xenograft model. As presented in Fig. 3A, the CD34/PAS ${ }^{+}$lumen structures were identified in tumors formed by normal U87 cells. Intracranial glioma xenografts of each group were shown in Fig. 3B, black arrows represented the tumors. In general, the tumors in AEG-1 shRNA group were smaller compared with those in the other two groups. The number of VM channels was significantly decreased in tumors formed by AEG-1 shRNA lentivirus-infected U87 cells $(\mathrm{F}=33.402, \mathrm{P}<0.01)$.

\section{Discussion}

Anti-angiogenic therapy inhibits angiogenesis, limiting the supply of oxygen and nutrients to tumor cells, inhibiting tumor growth (15). The effects of antiangiogenic drugs are unsatisfactory due to therapy resistance (16). Current antiangiogenic strategies mainly target the blood vessels formed by ECs; however, tumors rely on not only EC-based vessels, but the vasculogenic networks formed by tumor cells for nutrients (15). This type of structure is reported as VM, whereby the function of ECs is mimicked by tumor cells to form vasculogenic networks (6). VM has been observed in a variety of human tumors, such as gliomas, and
A

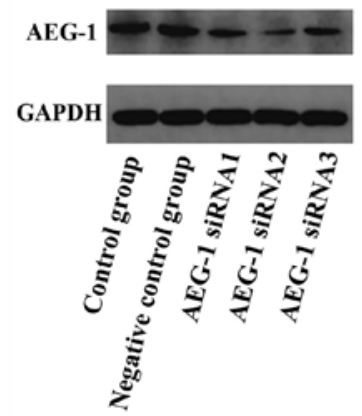

B

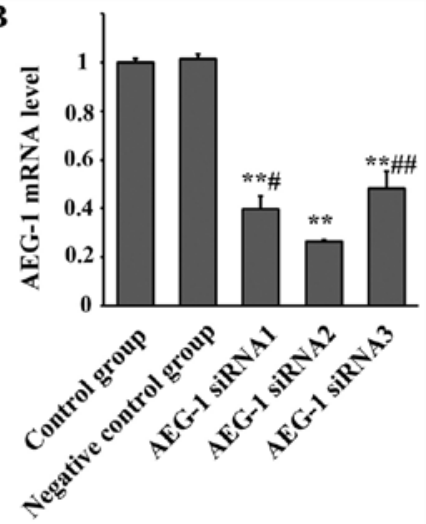

C
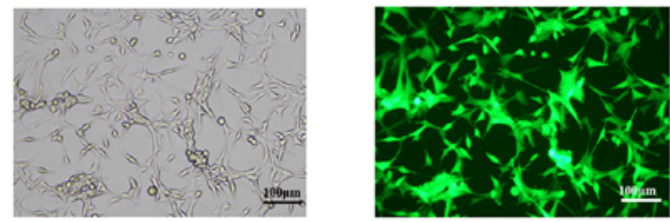

D
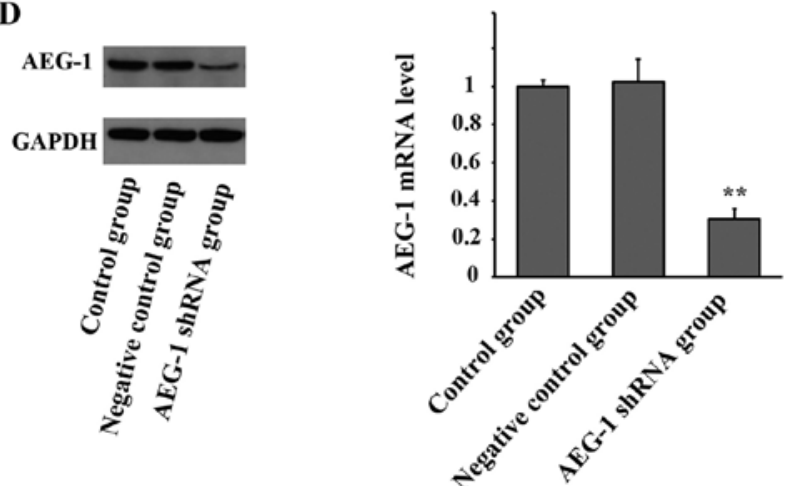

Figure 1. Downregulation of AEG-1 expression by siRNAs and AEG-1 shRNA lentivirals. siRNAs downregulated (A) AEG-1 protein and (B) mRNA expression levels. AEG-1 siRNA2 exhibited the highest knockdown efficiency among all of the three AEG-1 siRNAs and was selected to construct the AEG-1 shRNA lentiviral particle. (C) AEG-1 shRNA lentivirus-infected U87 cells. The stable transfected cells expressing green fluorescent protein were selected with $1 \mu \mathrm{g} / \mathrm{ml}$ puromycin. Scale bars represent $100 \mu \mathrm{m}$. (D) The AEG-1 expression was significantly downregulated in stably transfected U87 glioma cells, compared with the control group. ${ }^{* *} \mathrm{P}<0.01 \mathrm{vs}$. control group; ${ }^{\text {"P }}<<0.05,{ }^{\# \prime} \mathrm{P}<0.01$ vs. AEG-1 siRNA2. AEG-1, astrocyte elevated gene-1; siRNA, small interfering RNA; shRNA, short hairpin RNA.

is usually associated with a poor patient prognosis (7). Tumors exhibiting a high degree of VM appear to be more malignant, with an increased tendency for invasion and metastasis (17). Various molecular mechanisms and signaling pathways have been associated with VM formation and agents targeting these pathways have specific anti-tumor effects (7).

Among all the related molecules, MMP-2 appears to be crucial for the formation of VM. MMP-2 is associated with VM formation in several types of human tumors, including sebaceous carcinoma (18), intracranial hemangiopericytoma (19) and breast cancer (20). The mechanisms of action underlying the effects of MMP-2 on promoting the development of VM mainly involve the remodeling of the ECM (21). MMP-2 activation leads to the cleavage of the laminin-5 $\gamma 2$ chain into fragments, which are deposited in the ECM, contributing to ECM plasticity; cellular migration and invasion; and VM formation (22). The focal adhesion kinase-ERK1/2 (23) 
A

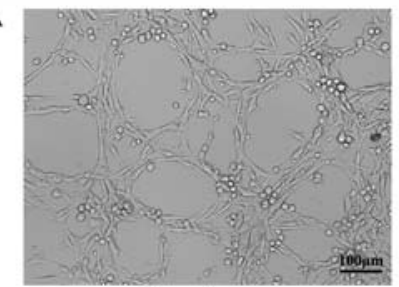

Control group

B

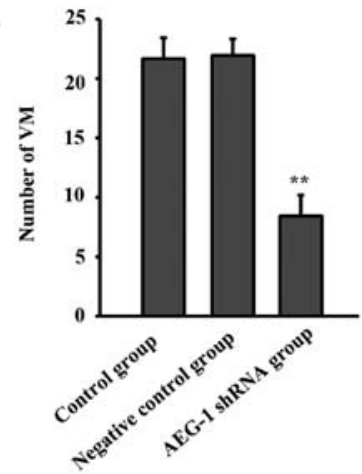

C

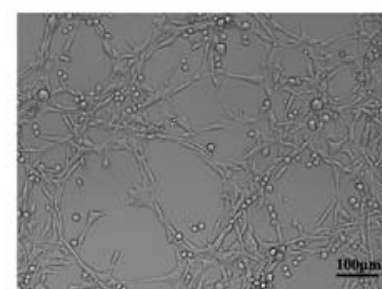

Negative control group MMP2

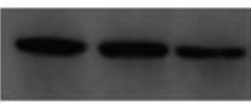

VEGF

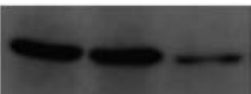

GAPDH

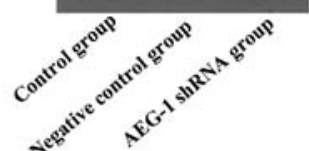

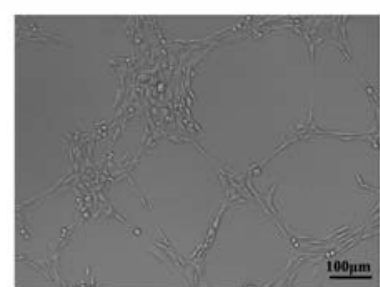

AEG-1 shRNA group

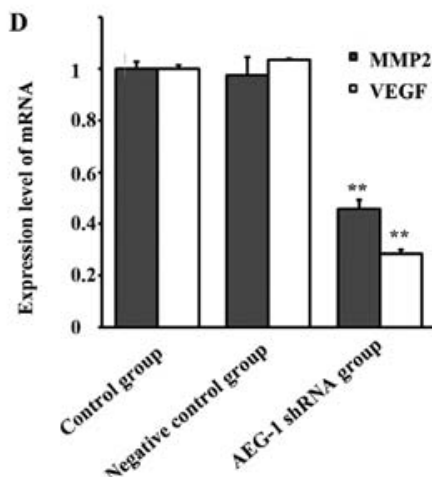

Figure 2. Downregulation of AEG-1 significantly inhibits the VM formation of U87 glioma cells in vitro. (A) In vitro VM formation of U87 glioma cells from each group. Scale bars represent $100 \mu \mathrm{m}$. (B) The VM counts of each group. (C) Western blotting of (D) quantification of VEGF and MMP-2 expression from the glioma cells of each group. The VM formation and the expression of VEGF and MMP-2 of glioma cells were significantly inhibited following infection with the AEG-1 shRNA lentivirus in vitro. ${ }^{* *} \mathrm{P}<0.01$ vs. control group. AEG-1, astrocyte elevated gene-1; shRNA, short hairpin RNA; VM, vasculogenic mimicry.

A

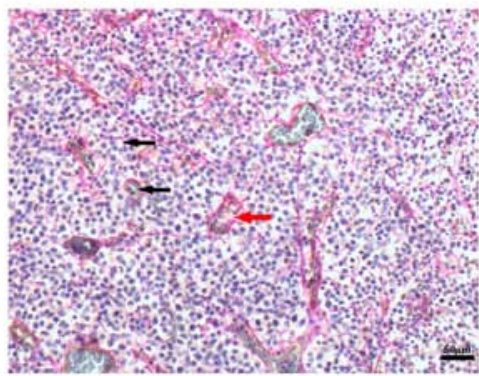

Control group

B

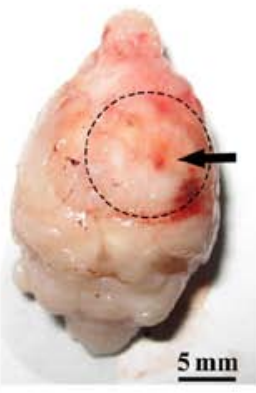

Control group

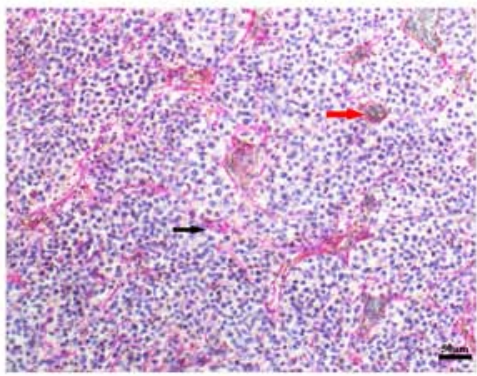

Negative control group

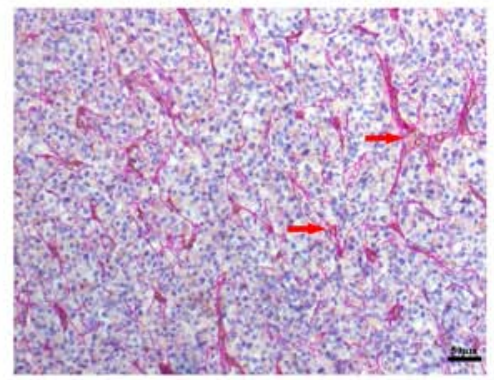

AEG-1 shRNA group

C

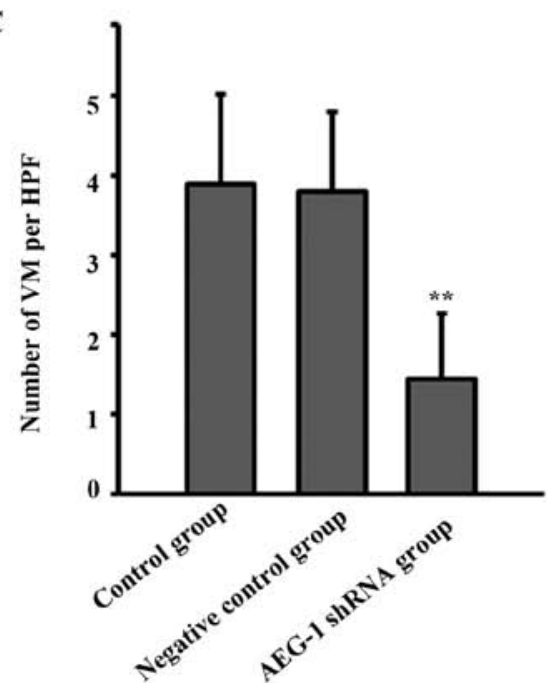

Figure 3. Effects of AEG-1 downregulation on VM formation in intracranial xenograft glioma models. (A) Representative images of CD34 and Periodic Acid-Schiff double-staining indicated the VM in each treatment group. Black arrows represent the VM, black arrows represent the tumor vessels. Scale bars represent $50 \mu \mathrm{m}$. (B) Intracranial xenograft glioma models of each group. Black arrows represent the tumors. Black circles indicate the location of the tumors. Scale bars represent $5 \mathrm{~mm}$. (C) Number of VM channels in each group. The number of VM channels was significantly decreased in tumors formed of AEG-1 short hairpin RNA lentivirus-infected U87 cells. ${ }^{* * *} \mathrm{P}<0.01$ vs. control group. VM, vasculogenic mimicry; AEG-1, astrocyte elevated gene-1; HPF, high power field; shRNA, short hairpin RNA; VM, vasculogenic mimicry. 
and PI3K/Akt signaling pathways (24) have been reported to regulate the expression and activation of MMP-2 during VM formation. The regulation of MMP-2 expression can notably affect VM formation $(20,25)$; thus, the anti-VM strategy aimed at MMP-2 may be effective. Certain studies have suggested that the inhibition of MMP-2 expression can significantly suppress VM formation $(26,27)$.

Several studies have demonstrated that VEGF is of great importance in the formation of VM. VEGF can upregulate the expression of VE-cadherin, ephrin-type A receptor 2 and MMPs, contributing to ECM remodeling and the development of VM (28). The ERK1/2 (25) and PI3K/Akt signaling pathways (29) have been reported to serve an essential role in VM formation induced by VEGF. Downregulation of VEGF has been reported to significantly inhibit VM formation $(29,30)$.

AEG-1 is considered as an oncogene in the induction of autophagy, invasion, metastasis, angiogenesis and drug resistance (8); however, the association between AEG-1 and VM formation remains unknown. The results of the present study demonstrated that AEG-1 may serve a crucial role for the formation of VM in glioma. The inhibition of AEG-1 expression by siRNA significantly suppressed VM formation of gliomas in vitro and in vivo. Additionally, the expression levels of VEGF and MMP-2 were significantly downregulated following the inhibition of AEG-1 expression. As VEGF and MMP-2 are two important inducers of VM (14), the mechanisms of VM inhibition through AEG-1 downregulation may partly be associated with the regulation of the two genes. However, whether the mechanism of action which underlies the regulation of VEGF and MMP-2 expression by AEG-1 in the development of VM in glioma requires further investigation. It has been suggested that AEG-1 may regulate the expression of VEGF and MMP-2 through the NF- $\kappa$ B pathway $(31,32)$.

In conclusion, in the present study, downregulation of AEG-1 expression was determined to significantly inhibit the development of VM in glioma in vitro and in vivo. These observations may be associated with the regulation of VEGF and MMP-2 expression; however, the underlying mechanism of action require further research. However, there were limitations in the present study. Because this is a preliminary study investigating the relationship between AEG-1 and VM formation in glioma, only one representative glioma cell line was used to demonstrate the hypothesis. More glioma cell lines and primary patient-derived cells will be used in further studies to verify the present results. Furthermore, the present study doesn't include any clinical data. Increasing the number study of clinical cases; investigating the relationship between AEG-1 expression, VM formation and prognosis; and analysing its clinical significance should be performed in the further studies

\section{Acknowledgements}

Not applicable.

\section{Funding}

The present study was supported by the Natural Science Foundation of Shaanxi Province (grant no. 2017JQ8037) and the National Natural Science Foundation of China (grant no. 81572485$)$.

\section{Availability of data and materials}

Not applicable.

\section{Authors' contributions}

CL performed animal studies and was a major contributor in writing the manuscript. JS performed molecular biology studies. LY performed statistical analysis. SG made substantial contributions to the design of the present study. All authors read and approved the final manuscript.

\section{Ethics approval and consent to participate}

This research has been approved by the Research Ethics Committee of Xi'an Jiaotong University Health Science Center (approval no. 2018048).

\section{Patient consent for publication}

Not applicable.

\section{Competing interests}

The authors declare that they have no competing interests.

\section{References}

1. Ostrom QT, Cioffi G, Gittleman H, Patil N, Waite K, Kruchko C and Barnholtz-Sloan JS: CBTRUS Statistical Report: Primary Brain and Other Central Nervous System Tumors Diagnosed in the United States in 2012-2016. Neuro-oncol 21 (Suppl 5): v1-v100, 2019.

2. Stupp R, Taillibert S, Kanner AA, Kesari S, Steinberg DM, Toms SA, Taylor LP, Lieberman F, Silvani A, Fink KL, et al: Maintenance therapy with tumor-treating fields plus temozolomide vs temozolomide alone for glioblastoma: a randomized clinical trial. JAMA 314: 2535-2543, 2015.

3. Komori T: The 2016 WHO Classification of Tumours of the Central Nervous System: The Major Points of Revision. Neurol Med Chir (Tokyo) 57: 301-311, 2017.

4. Ameratunga M, Pavlakis N, Wheeler H, Grant R, Simes J and Khasraw M: Anti-angiogenic therapy for high-grade glioma. Cochrane Database Syst Rev 11: CD008218, 2018.

5. Blumenthal DT, Kanner AA, Aizenstein O, Cagnano E, Greenberg A, Hershkovitz D, Ram Z and Bokstein F: Surgery for Recurrent High-Grade Glioma After Treatment with Bevacizumab. World Neurosurg 110: e727-e737, 2018.

6. El Hallani S, Boisselier B, Peglion F, Rousseau A, Colin C, Idbaih A, Marie Y, Mokhtari K, Thomas JL, Eichmann A, et al: A new alternative mechanism in glioblastoma vascularization: Tubular vasculogenic mimicry. Brain 133: 973-982, 2010.

7. Chen YS and Chen ZP: Vasculogenic mimicry: A novel target for glioma therapy. Chin J Cancer 33: 74-79, 2014.

8. Zou M, Zhu W, Wang L, Shi L, Gao R, Ou Y, Chen X, Wang Z, Jiang A, Liu K, et al: AEG-1/MTDH-activated autophagy enhances human malignant glioma susceptibility to TGF- 31 -triggered epithelial-mesenchymal transition. Oncotarget 7: 13122-13138, 2016.

9. Noch E, Bookland M and Khalili K: Astrocyte-elevated gene-1 (AEG-1) induction by hypoxia and glucose deprivation in glioblastoma. Cancer Biol Ther 11: 32-39, 2011.

10. Yang Y, Wu J, Guan H, Cai J, Fang L, Li J and Li M: MiR-136 promotes apoptosis of glioma cells by targeting AEG-1 and Bcl-2. FEBS Lett 586: 3608-3612, 2012.

11. Livak KJ and Schmittgen TD: Analysis of relative gene expression data using real-time quantitative PCR and the 2(-Delta Delta C(T)) Method. Methods 25: 402-408, 2001.

12. Liang C, Guo S and Yang L: Effects of all trans retinoic acid on VEGF and HIF $1 \alpha$ expression in glioma cells under normoxia and hypoxia and its anti angiogenic effect in an intracerebral glioma model. Mol Med Rep 10: 2713-2719, 2014. 
13. Francescone RA, Faibish M and Shao R: A matrigel-based tube formation assay to assess the vasculogenic activity of tumor cells. J Vis Exp 55: e3040, 2011.

14. Hernández de la Cruz ON, López-González JS, García-Vázquez R, Salinas-Vera YM, Muñiz-Lino MA, Aguilar-Cazares D, López-Camarillo C and Carlos-Reyes Á: Regulation networks driving vasculogenic mimicry in solid tumors. Front Oncol 9: $1419,2020$.

15. Haibe Y, Kreidieh M, El Hajj H, Khalifeh I, Mukherji D, Temraz S and Shamseddine A: Resistance Mechanisms to Anti-angiogenic Therapies in Cancer. Front Oncol 10: 221, 2020.

16. Wu HB, Yang S, Weng HY, Chen Q, Zhao XL, Fu WJ, Niu Q Ping YF, Wang JM, Zhang X, et al: Autophagy-induced KDR/VEGFR-2 activation promotes the formation of vasculogenic mimicry by glioma stem cells. Autophagy 13: 1528-1542, 2017.

17. $\mathrm{Ge} \mathrm{H}$ and Luo $\mathrm{H}$ : Overview of advances in vasculogenic mimicry - a potential target for tumor therapy. Cancer Manag Res 10: 2429-2437, 2018

18. Xu X, Jia R, Zhou Y, Song X and Fan X: Investigation of vasculogenic mimicry in sebaceous carcinoma of the eyelid. Acta Ophthalmol 88: e160-e164, 2010.

19. Zhang Z, Han Y, Zhang K and Teng L: Investigation of vasculogenic mimicry in intracranial hemangiopericytoma. Mol Med Rep 4: 1295-1298, 2011

20. Robertson FM, Simeone AM, Lucci A, McMurray JS, Ghosh S and Cristofanilli M: Differential regulation of the aggressive phenotype of inflammatory breast cancer cells by prostanoid receptors EP3 and EP4. Cancer 116 (Suppl): 2806-2814, 2010.

21. Hendrix MJ, Seftor EA, Hess AR and Seftor RE: Vasculogenic mimicry and tumour-cell plasticity: Lessons from melanoma. Nat Rev Cancer 3: 411-421, 2003.

22. Seftor RE, Seftor EA, Koshikawa N, Meltzer PS, Gardner LM, Bilban M, Stetler-Stevenson WG, Quaranta V and Hendrix MJ: Cooperative interactions of laminin 5 gamma2 chain, matrix metalloproteinase-2, and membrane type-1-matrix/metalloproteinase are required for mimicry of embryonic vasculogenesis by aggressive melanoma. Cancer Res 61: 6322-6327, 2001.

23. Qiao L, Liang N, Zhang J, Xie J, Liu F, Xu D, Yu X and Tian Y: Advanced research on vasculogenic mimicry in cancer. J Cell Mol Med 19: 315-326, 2015.
24. Hess AR, Seftor EA, Seftor RE and Hendrix MJ: Phosphoinositide 3-kinase regulates membrane type 1-matrix metalloproteinase (MMP) and MMP-2 activity during melanoma cell vasculogenic mimicry. Cancer Res 63: 4757-4762, 2003.

25. Liu Y, Li F, Yang YT, Xu XD, Chen JS, Chen TL, Chen HJ, Zhu YB, Lin JY, Li Y, et al: IGFBP2 promotes vasculogenic mimicry formation via regulating CD144 and MMP2 expression in glioma. Oncogene 38: 1815-1831, 2019.

26. Bai R, Ding T, Zhao J, Liu S, Zhang L, Lan X, Yu Y and Yin L: The effect of PI3K inhibitor LY294002 and gemcitabine hydrochloride combined with ionizing radiation on the formation of vasculogenic mimicry of Panc-1 cells in vitro and in vivo. Neoplasma 63: 80-92, 2016.

27. Zhang S, Li M, Gu Y, Liu Z, Xu S, Cui Y and Sun B: Thalidomide influences growth and vasculogenic mimicry channel formation in melanoma. J Exp Clin Cancer Res 27: 60, 2008.

28. Wang JY, Sun T, Zhao XL, Zhang SW, Zhang DF, Gu Q, Wang XH, Zhao N, Qie S and Sun BC: Functional significance of VEGF-a in human ovarian carcinoma: Role in vasculogenic mimicry. Cancer Biol Ther 7: 758-766, 2008.

29. Qin L, Ren Y, Chen AM, Guo FJ, Xu F, Gong C, Cheng P, Du Y and Liao H: Peroxisome proliferator-activated receptor $\gamma$ ligands inhibit VEGF-mediated vasculogenic mimicry of prostate cancer through the AKT signaling pathway. Mol Med Rep 10: 276-282, 2014.

30. Mei J, Gao Y, Zhang L, Cai X, Qian Z, Huang H and Huang W: VEGF-siRNA silencing induces apoptosis, inhibits proliferation and suppresses vasculogenic mimicry in osteosarcoma in vitro. Exp Oncol 30: 29-34, 2008

31. Yu JQ, Zhou Q, Zhu H, Zheng FY and Chen ZW: Overexpression of astrocyte elevated gene-1 (AEG-1) in cervical cancer and its correlation with angiogenesis. Asian Pac J Cancer Prev 16: 2277-2281, 2015

32. Huang LL, Wang Z, Cao CJ, Ke ZF, Wang F, Wang R, Luo CQ, Lu X and Wang LT: AEG-1 associates with metastasis in papillary thyroid cancer through upregulation of MMP2/9. Int JOncol 51: 812-822, 2017.

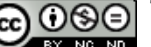

This work is licensed under a Creative Commons Attribution-NonCommercial-NoDerivatives 4.0 International (CC BY-NC-ND 4.0) License. 